\title{
TERCEIRIZAÇÃO EM INFORMÁTICA SOB A ÓTICA DO PRESTADOR DE SERVIÇOS
}

Jaci Corrêa Leite

Professor Adjunto do Departamento de Informática e Métodos

Quantitativos da EAESP/FGV.

RESUMO: Este trabalho descreve uma pesquisa de campo feita no Brasil em 1996. Foram consultadas empresas prestadoras de serviços, buscando melhor compreender esse lado da relação numa parceria cujo objeto são os serviços de informática. Trata-se de um aspecto que até então não havia sido abordado na realidade brasileira e que trouxe à luz importantes conclusões que facilitam o estabelecimento de processos de terceirização.

ABSTRACT: This text describes an empirical research conducted in Brazil in 1996, comprehending information service companies in order to better understand their side in a partnership relation in which the IT (Information Technology) services are the subject. This is a viewpoint not approached before in the Brazilian context. The study reveals important conclusions which make easier the understanding of outsourcing.

PALAVRAS-CHAVE: informática, terceirização, administração de sistemas de informação, gestão de informática, outsourcing.

KEY WORDS: information systems, information systems management, information technology management, outsourcing. 
1. KEYES, Jessica. Infotrends: the competitive use of information. New York, USA: McGraw-Hill, 1993

2. LEITE, Jaci Corrêa. Terceirização em informática no Brasil. São Paulo: NPP - Núcleo de Pesquisas e Publicações da EAESP/FGV, 1995

3. CHAVES, Sidney. Terceirização das atividades de informática. Beeline, v. 1 n. 11, dez./1992, D. 3-4; LACITY, Mary Cecelia, HIRSCHHEIM, Rudy. Information systems outsourcing. England: John Wiley \& Sons, Chichester, 1993; LEITE, Jaci Corrêa. Terceirização em informática. São Paulo: Makron Books, 1994.

4. WANG, Charles B. O novo papel do executivo de informática. São Paulo: Makron Books, 1995.

5. BYTE. Casamento bem-sucedido. Byte Brasil, jun./1995, p. 80-96; CROSS, John. IT outsourcing: British petroleum's competitive approach, Harvard Business Review, may-june 1995, p. 94-103; GOLDMAN, Stanley J. Creative Outsourcing. Datamation, july 15, 1995 , p. 84; KAY, Emily. Should you outsource your Intranet?. Datamation, february 1 1996, p. 37-4; LACITY, Mary Cecelia WILCOCKS, Leslie P., FEENY, David F. IT Outsourcing: maximize flexibility and control. Harvard Business Review, mayjune 1995, p. 84-92; MCFARLAN, F Warren, NOLAN, Richard L. How to manage an IT outsourcing alliance. Sloan Management Review, winter 1995, p. 9 23.

6. LEITE, Jaci Corrêa. Op. cit., 1985
Keyes $^{1}$ relata que a terceirização em informática no conceito atual começou no final dos anos 80, quando a Kodak contratou a IBM, Digital e Businessland, que passaram a responder por tudo o que dizia respeito a informática e telecomunicações. A inovação abriu caminho para que outras empresas terceirizassem, no todo ou em parte, suas atividades de informática. O movimento ganhou força no início dos anos 90 e, por volta de 1992 ou 1993, consolidou-se de fato como uma tendência. No contexto brasileiro, um estudo realizado junto a 125 empresas $^{2}$ revela que quatro em cada cinco organizações estão, com menor ou maior intensidade, lançando mão desse recurso.

A terceirização em informática difere daquela ligada a serviços de infra-estrutura e apoio, tais como limpeza e segurança. ${ }^{3}$ Nestes, a motivação básica está em reduzir custos e focalizar as atividades-fim da organização. Mas a terceirização em informática freqüentemente avança sobre terreno estratégico: os riscos são maiores e o custo assume papel secundário. Por isso, a avaliação custo-benefício perde a objetividade: os fatores intervenientes são muitos e interagem segundo uma complexa e intrincada rede de interdependências.

Tal prática tem sido vista ora como opção a ser evitada, ${ }^{4}$ ora como tendência irreversível e implicitamente benéfica. ${ }^{5} \mathrm{O}$ citado estudo no contexto brasileiro ${ }^{6}$ mostra que mais de $40 \%$ das empresas que terceirizam declaram a existência de dificuldades de diversas naturezas, desde problemas internos até as várias facetas do relacionamento com o parceiro. $O$ curioso é que essa questão é sempre examinada por um único lado: o ponto de vista da empresa que terceiriza, quase sempre apresentada nas entrelinhas como uma vítima, potencial ou real, sujeita à incompetência e à má vontade de um prestador de serviços que estaria sempre prestes a atacar.

Possivelmente, porém, grande parte dos problemas que ocorrem não são causados pelo prestador de serviços, mas pelo cliente. Se há prestadores de serviços inidôneos e incompetentes, também não são poucos os clientes ima- turos, com excesso de expectativas e falta de comprometimento, que tudo esperam mas nada querem dar numa relação bilateral. Enfim, se está diante de um relacionamento que deveria ser altamente profissional mas que, infelizmente, mostra um forte componente emocional. Mas é importante notar que todos os envolvidos nessa relação correm riscos: assim como o tomador de serviços se expõe à dependência em relação a terceiros, também o prestador fica sujeito ao desgaste institucional de uma relação malsucedida. Relações deterioradas levam a problemas cuja dimensão dificilmente poderia ser antecipada, com elevado potencial de perdas para ambos os lados.

Assim como, para o contratante, a terceirização em informática difere daquela praticada em atividades de infra-estrutura, o prestador de serviços de informática também enfrenta problemas distintos daqueles vividos por empresas de segurança, limpeza e similares:

- como a tecnologia de informação torna-se cada vez mais abrangente, é preciso dispor de uma enorme gama de perfis profissionais muito qualificados, por vezes parcialmente ociosos;

- além da crescente abrangência, o ritmo de introdução de novidades é elevado, exigindo permanente esforço de reciclagem;

- num verdadeiro desestímulo ao bom desempenho, o prestador de serviços de informática invariavelmente se vê diante da situação em que seus serviços são avaliados basicamente pelo preço, quando há outros fatores muito mais importantes, tais como a inovação, a qualidade, a flexibilidade, a garantia de evolução etc.;

- é muito frequiente o prestador de serviços ser visto pelo cliente (ou, pelo menos, por uma 
parcela significativa de seu pessoal) como um "vilão", intruso, indigno de confiança, um verdadeiro inimigo a ser boicotado.

Como não se conseguiu localizar um único trabalho que abordasse a problemática diretamente do ponto de vista do prestador de serviços, concebeu-se este estudo. Compreender os anseios e expectativas deste segundo lado é uma forma de melhorar o relacionamento entre as partes, diminuir a tensão e potencializar os benefícios da terceirização em informática.

\section{METODOLOGIA}

Este trabalho seguiu a tradicional abordagem de duas frentes paralelas que se complementam mutuamente: pesquisa bibliográfica e investigação empírica da realidade, procurando verificar, na prática, a validade $\mathrm{e}$ aplicabilidade dos conceitos.

Apesar da bibliografia sobre o tema ser relativamente escassa, há vários trabalhos que se complementam uns aos outros, com enfoques diferenciados, apresentando a questão sob o ponto de vista da empresa que contrata serviços. Porém, durante a realização desta pesquisa, só foi possível identificar um

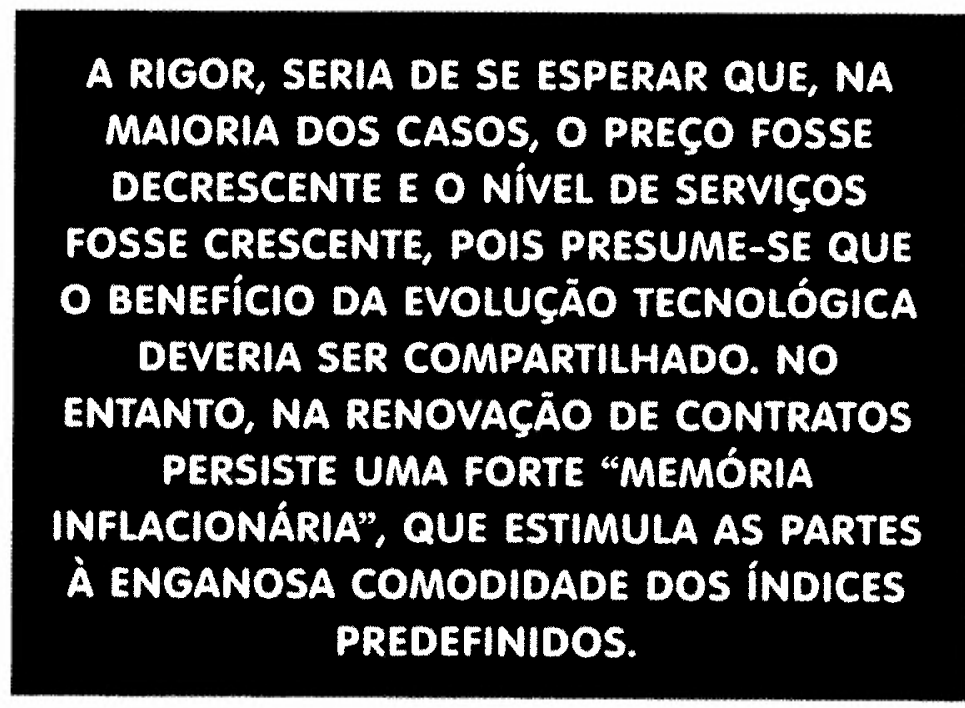
único texto que trata a problemática da terceirização em informática sob a perspectiva do prestador de serviços. ${ }^{7}$ No entanto, tal trabalho está focado no estabelecimento de pequenas empresas atuando na produção de software, analisando pontos como oportunidades, mercados, análise econômico-financeira e temas afins. Paralelamente, diversos textos lidos apresentam, nas entrelinhas, traços relevantes sobre o fornecedor, ${ }^{8}$ ao passo que outros chegam a tratar o assunto sob este ponto de vista, embora de forma um tanto quanto tangencial. ${ }^{9}$

Quanto ao levantamento da situação no mundo real, havia dois pontos principais: a definição do instrumento de levantamento e a identificação do universo a pesquisar. Em termos de instrumento para levantamento, optou- versas dimensões: nacional versus estrangeira, pequena versus grande, focalizada versus abrangente. Buscou-se uma amostra que fosse o mais representativa possível de todos os segmentos do mercado, cobrindo desde as grandes empresas com ampla gama de serviços até aquelas pequenas e especializadas em nichos específicos. Pela natureza qualitativa do trabalho, uma amostra ampla seria desaconselhável, pois inviabilizaria o levantamento, ao mesmo tempo que poderia complicar excessivamente o processo de análise. A proposta inicial foi de um universo de quinze empresas privadas (foram descartadas as empresas estatais). Para assegurar a representatividade, foram preliminarmente selecionados todos os líderes de mercado nos segmentos se por entrevistas pessoais com roteiro previamente estabelecido, conforme as abordagens de Chaves, ${ }^{10}$ Coopers \& Librand ${ }^{11}$ e outros. Deixou-se ampla margem de abertura para que viessem à tona quaisquer pontos relevantes não previstos. Como o estudo de Lacity \& Hirschheim, ${ }^{12}$ este trabalho baseiase essencialmente em análises qualitativas. As inferências e conclusões aqui apresentadas não se prendem a análises estatísticas, até porque, pela própria natureza do enfoque e pelo número relativamente limitado de entrevistas realizadas, qualquer conclusão fundamentada em análises estatísticas tenderia a ficar enfraquecida.

Quanto ao universo a pesquisar, o mercado se caracteriza por várias categorias de empresas, que podem ser agrupadas segundo di-
7. FAGUNDES, Jorge. 0 setor de software sob encomenda e as micro e pequenas empresas. Economia \& Empresa, v. $2, n$. 4, out.-dez. 1995, p. 60-76.

8. BYTE, op. cit.; GOLDSMITH, Robin F Confidently outsourcing software development. Journal of Systems Management, april 1994, p. 12-17 LACITY, Mary Cecelia, HIRSCHHEIM Rudy. The information systems outsourcing bandwagon. Sloan Management Review, fall 1993, p. 73-86

9. MACFARLAN \& NOLAN. Op. cit., 1995.

10. CHAVES. Op. cit., 1992.

11. COOPERS \& LIBRAND. A tercelrização nas empresas. $2^{a}$ Pesquisa Coopers \& Librand, São Paulo, 1992.

12. LACITY \& HIRSCHHEIM. Op. cit., 1993 
grande e médio, bem como algumas empresas de atuação nitidamente focada em nichos específicos.

\section{CARACTERIZAÇÃO DA AMOSTRA}

As entrevistas foram feitas em 1996. Quanto ao tipo de organização societária e origem do capital predominante, as empresas analisadas apresentam a distribuição apresentada na figura 1 .

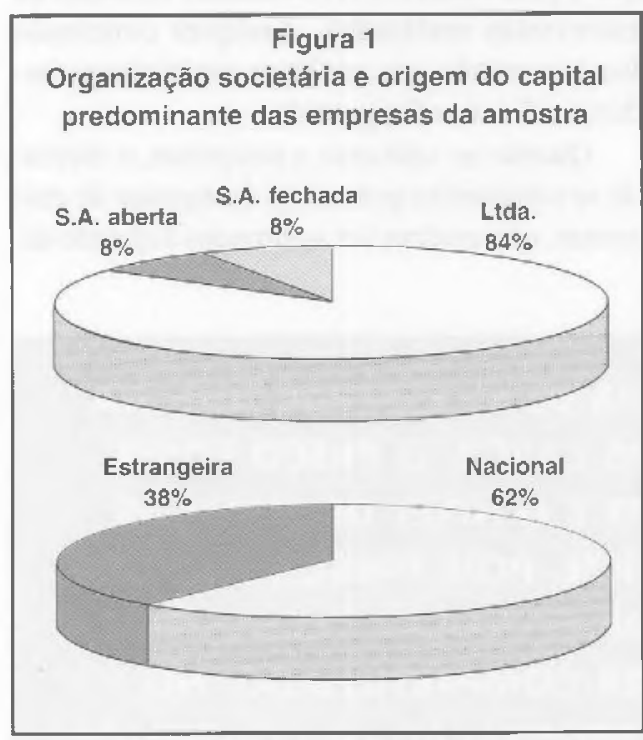

Quanto ao principal foco de atuaçăo das empresas, a amostra revelou o perfil demonstrado na figura 2, na qual, onde se lê outsourcing, deve-se subentender uma atuação bastante ampla, abrangendo todos os serviços.

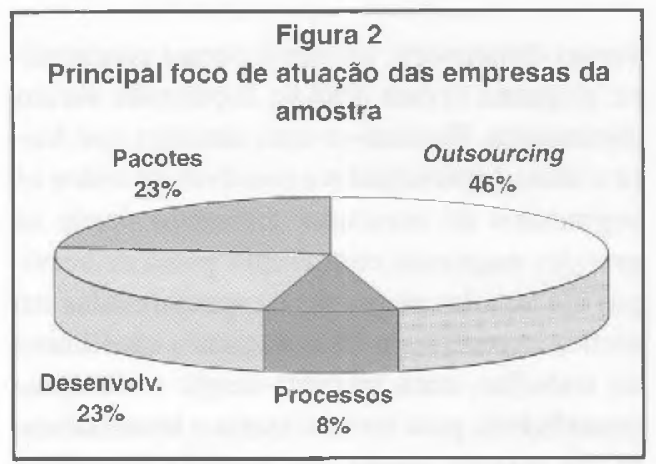

Quanto ao faturamento de cada empresa, o mercado é bastante reservado e praticamente nenhum entrevistado quis abrir seus dados. Por isso, com base em informações coletadas junto ao mercado, pôde-se fazer uma aproxima- ção: o demonstrativo a seguir (quadro 1) tem como finalidade oferecer uma idéia sobre o universo pesquisado. Dada a impossibilidade de se ter uma quantificaçăo absolutamente exata, optoul-se pelo delineamento de um cenário aproximado que permitisse melhor contextualizar a situação em que foi feito o estudo.

\section{Quadro 1}

Faturamento estimado para 1996 (no Brasil)

\begin{tabular}{|l|r|}
\hline Minimo & US\$ 4 milhôes \\
\hline Média & US\$ 40 milhōes \\
\hline Máximo & USS 130 milhōes \\
\hline Abaixo de US\$ 15 milhões & $31 \%$ \\
\hline $\begin{array}{l}\text { Entre US\$ } 15 \text { milhões } \\
\text { e US\$ } 30 \text { milhōes }\end{array}$ & $23 \%$ \\
\hline $\begin{array}{l}\text { Entre US\$ } 30 \text { milhōes } \\
\text { e US\$ 70 milhōes }\end{array}$ & $23 \%$ \\
\hline Acima de US\$ 70 milhōes & $23 \%$ \\
\hline
\end{tabular}

Pode-se inferir que a amostra corresponde a uma razoável aproximação do que se poderia chamar de padrão de mercado, desde que se desconsiderem os prestadores de serviços muito pequenos, ou seja, aqueles de faturamento inferior a US\$250.000 mensais. Este último segmento, muito pulverizado, desempenha importante papel na prestação de serviços, mas ainda apresenta muitas características de gestäo pessoal, quase artesanal, e não seria razoável comparar seus problemas com aqueles vividos por empresas maiores, mais profissionalizadas.

\section{RESULTADOS OBSERVADOS}

Os resultados observados no levantamento empírico estão relacionados a seguir, divididos em dezesseis grandes temas.

\section{Focalização de serviços}

Um dos aspectos interessantes com relação aos prestadores de serviços refere-se tanto à política quanto a serviços focalizados ou diversificados. Há duas posturas distintas: a primeira é fornecer a mais ampla gama de serviços possível, estando a empresa, portanto, apta a suprir virtualmente todas as necessidades do cliente; a segunda é especializar-se num nicho específico de mercado, procurando a excelência nesse segmento em particular. Notese que a postura de diversificação exige estrutura substancialmente maior do que a 
exigida pela postura de focalização. Por isso, é natural que os diversificados concentremse entre as empresas maiores, enquanto que os focalizados concentrem-se prioritariamente entre as menores.

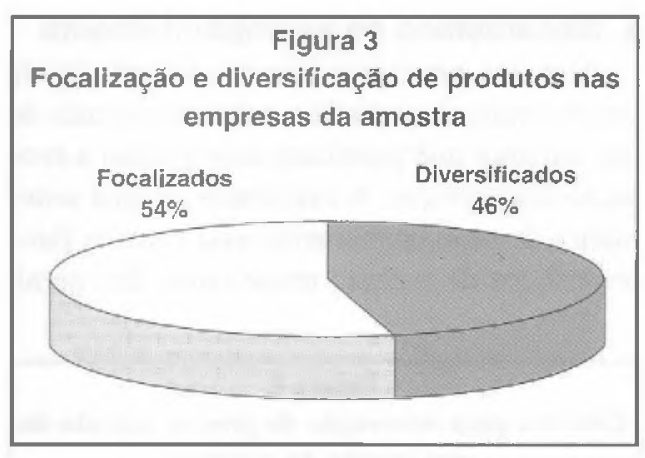

\section{Concentração de clientes}

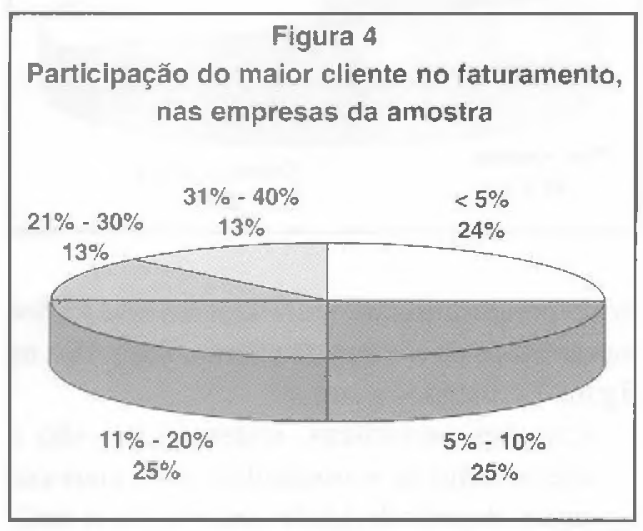

Assim como as empresas que terceirizam preocupam-se com a criaçăo de vínculos de dependência, ${ }^{13}$ os prestadores de serviços procuram não concentrar negócios com um único cliente. Em metade dos prestadores de serviços, o maior cliente representa, no máximo, $10 \%$ sobre o faturamento, ao passo que apenas $13 \%$ têm tal participaçāo entre 31 e $40 \%$. Isso é ainda mais significativo quando se considera que parte das empresas da amostra são coligadas a grandes grupos empresariais. $\mathrm{O}$ interessante é que, mesmo nesses casos, nota-se a preocupação no sentido de ampliar a base de clientes, buscando, assim, minimizat o risco.

\section{Percepção quanto à concorrência}

Um aspecto sobre o qual havia dúvida era a formá como o prestador de serviços vê a concorrência. Para esclarecer a questão, foi solicitado que cada entrevistado mencionasse seus principais concorrentes no Brasil (e, se fosse o caso, também no exterior). Pediu-se que cada um apresentasse um comparativo, ainda que aproximado, em termos de portes relativos e participação $n o$ mercado. O resultado observado mostra que as empresas têm razoável percepção sobre quem são, de fato, seus concorrentes: em quase todos os casos em que uma empresa foi citada como concorrente, a menção foi recíproca. O que é óbvio já que, provavelmente, quando vão conquistar um novo cliente, disputam mais ou menos com os mesmos concorrentes. Apesar disso, as empresas entrevistadas não têm (ou fingem não ter) conhecimento quanto ao peso relativo de seus concorrentes e, por extensão, quanto ao seu próprio market share, mostrando a falta de maturidade do mercado: parece não haver qualquer fonte de informações confiável com relação a quem está conseguindo o quê. Observa-se um claro descompasso em relação aos Estados Unidos, onde existem diversas publicações com o ranking dos prestadores de serviços.

\section{Definição de regras para o relacionamento bilateral}

O estabelecimento de regras para o relacionamento bilateral se faz por um contrato entre as partes. Leite ${ }^{14}$ enfatiza que esse é um dos quatro fatores críticos para o sucesso da terceirização em informática, ao passo que Lacity \& Hischheim ${ }^{15}$ mostram que o contrato pode ser uma fonte de dores de cabeça para o cliente (subentende-se nas entrelinhas que o mesmo acontece, talvez em menor grau, também com o prestador de serviços). Há três abordagens básicas para se estabelecer um conjunto de regras que orientarão a parceria:

- pode-se partir de un contrato-padrão redigido pelo fornecedor, ao qual o cliente adere, com menor ou maior grau de liberdade de propor alterações;

- pode acontecer que o cliente tenha um maior poder de barganha e proponha o contrato, que o fornecedor aceitará com alguns ajustes;

- finalmente, existem situações em que se trabalha com uma análise específica, definindo-se a redação caso a caso, geralmente sob coordenação do prestador de serviços. Como se pode observar no gráfico anterior, em praticamente dois terços dos casos, é o fornecedor quem apresenta uma primeira proposta de contrato. Em quase um quarto, é o cliente quem traz sua minuta. $\mathrm{E}$, finalmente, em um sexto dos casos adota-se a modalidade do contrato específico. É evidente que a
13. LEITE, Jacl Corrễa. Op. cilt., 1995. 14. LEITE, Jaci Corrêa. Op. cit.. 1994. 15. LACITY \& HIRSCHHEIM. Op. CIt, 1993.

RAE - v. 37 - n. 4 - Out./Dez. 1997 


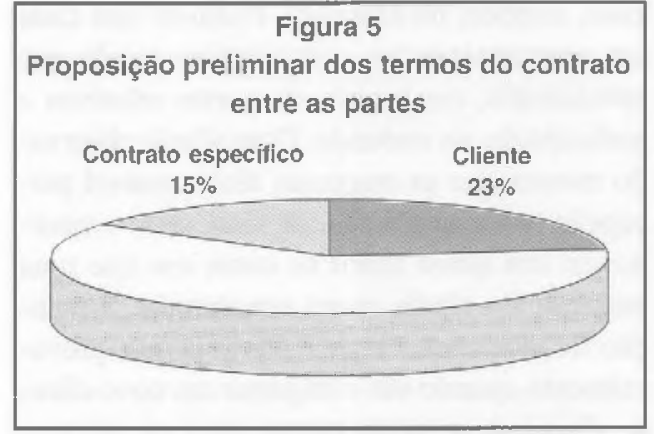

primeira proposta, seja de quem for, é trabathada pelo outro lado, na maior parte das vezes com um razoável grau de flexibilidade. Mas quem faz a proposição inicial fica mais confortável, pois, por maiores que sejam os ajustes, presume-se que a maior parte permaneça. Foi inclusive mencionado que pequenos clientes devem sujeitar-se à assinatura de contratos de adesão, sem virtualmente nenhuma margem de manobra.

\section{Renovações de contratos}

A renovação do contrato normalmente ocorre após um razoável período depois de iniciado o relacionamento entre as partes. Frequientemente, esse periodo ultrapassa um ano. No momento da renovação, há dois grandes componentes em jogo: o nível de serviços e o preço. Ambos são fortemente influenciados pela evolução da tecnologia, principalmente nos casos em que a parceria envolve também processamento e linhas de comunicação.

A rigor, seria de se esperar que, na maioria dos casos, o preço fosse decrescente e o nível de serviços fosse crescente, pois presume-se que o benefício da evolução tecnológica devetia ser compartilhado. Mas, conforme destaca Leite, ${ }^{16}$ na renovação de contratos persiste uma forte "memória inflacionária", que estimula as partes à enganosa comodidade dos índices predefinidos. Nota-se uma especial predileção pelo IGP-DI, que, objetivamente, não tem a mais tênue ligação com planilhas de custos dos serviços de informática. Cumpre destacar que algumas empresas declararam que a sistemática depende do poder de barganha do cliente, oferecendo-se maior flexibilidade àqueles que tenham maior potencial de retorno.

Note-se que o conjunto IGP-DI (31\%) mais outros índices predefinidos $(23 \%)$ responde por mais da metade dos casos, enquanto que a apresentação de planilhas de custos (a rigor, o cri- gado por menos de um terço dos prestadores de serviços (figura 6). O surpreendente é que, aparentemente, o cliente aceita esta disfunção sem maiores questionamentos, mais uma vez ratificando a pouca maturidade do mercado.

\section{Mecanismos de acompanhamento}

Um dos principais fatores de redução da tensão entre as partes é o estabelecimento de mecanismos que permitam acompanhar a evolução dos serviços. A existência de uma sistemática de acompanhamento está entre os fatores críticos de sucesso nesse ramo. Em geral,

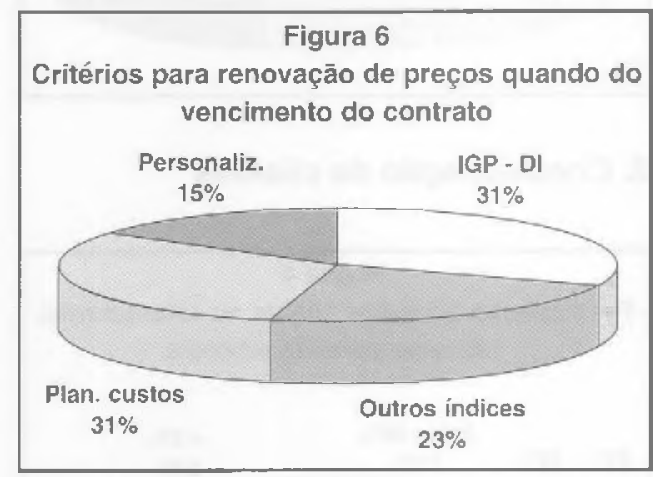

as empresas utilizam simultaneamente vários mecanismos de acompanhamento, ilustrados na figura 7 e listados a seguir:

- reuniões periódicas, sistemáticas, são o mecanismo de acompanhamento mais comum. A periodicidade mínima varia muito (desde semanal até trimestral). Paralelamente, é bastante usual que reuniões mais freqüentes, geralmente no nível gerencial, sejam entremeadas por uma reunião semestral ou anual com o top management do cliente;

- relatórios periódicos (geralmente mensais) são utilizados por metade das empresas: trata-se de urn resumo genérico, listando o que foi realizado (por vezes comparando ao previsto) e destacando eventuais pendências. Algumas empresas mantêm também relatótios específicos sobre custos incorridos e nível de serviço prestado;

- levantamentos sistemáticos de nível de satisfação, assim como o estabelecimento de milestones (pontos de acompanhamento que indicam a evolução do trabalho) são adotados por apenas um sexto das empresas entrevistadas. É surpreendente que esses dois mecanismos, bastante utilizados no exterior, sejam tão pouco populares no con- 


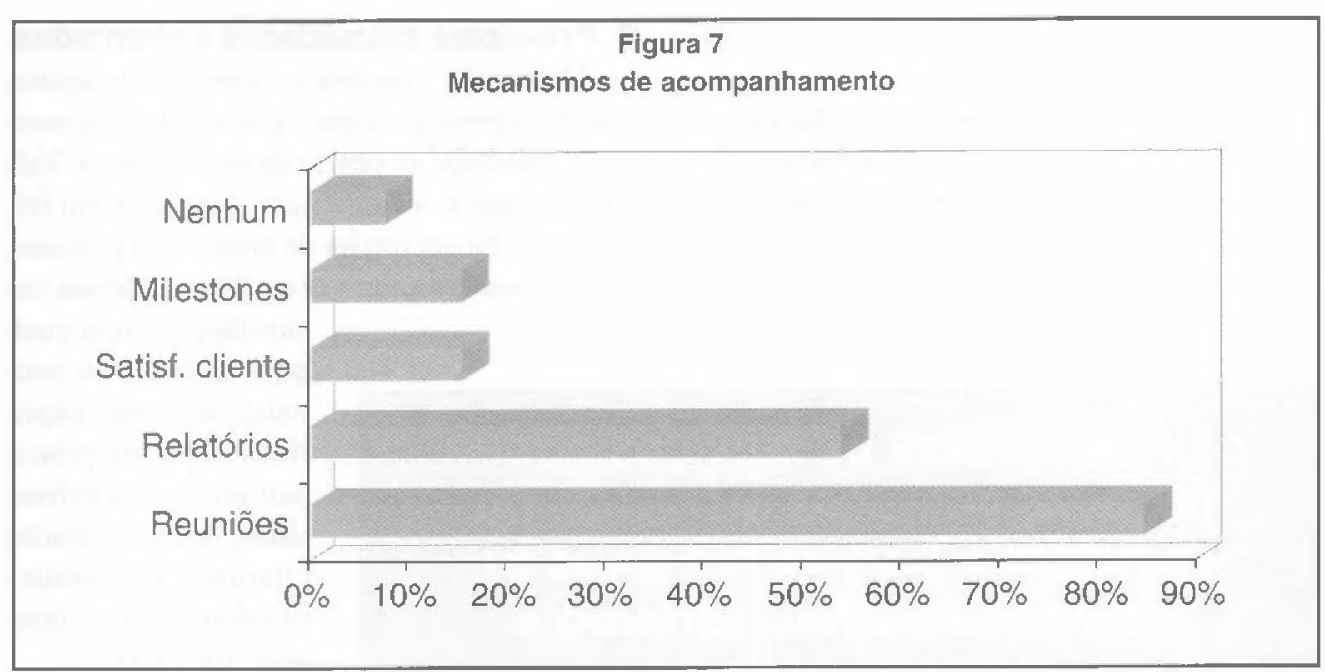

texto brasileiro. Isso, combinado ao elevado índice de reuniões de acompanhamento, parece indicar que o relacionamento entre o cliente e o prestador de serviços ainda guarda elevada dose de subjetividade.

\section{Controle de qualidade}

Controle de qualidade não é o mesmo que mecanismos de acompanhamento. Estes últimos se referem à execução ou não do que foi proposto, enquanto que o controle de qualidade focaliza as características do resultado final obtido. Numa outra perspectiva, um trata do o que, outro do como está sendo feito. Notase em todos os prestadores de serviços uma explícita preocupação no sentido de desenvolver mecanismos que possam assegurar a qualidade para o cliente. Isso é muito natural e seria mesmo de se esperar, uma vez que a qualidade é a maior garantia para se manter o cliente num contex to de longo prazo.

Conforme a figura 8 , nota-se que há várias formas de controle de qualidade:

- metodologia própria é a sistemática mais adotada, mas a homogeneidade é apenas aparente. Algumas empresas embutem, nessa metodologia, diagnóstico sistemático de problemas; outras mostram grande preocupação quanto ao desempenho do sistema; outras priorizam a produtividade de seu pessoal; outras colocam em primeiro lugar o tempo de atendimento de reclamações; e assim por diante;

- relatórios periódicos, utilizados por um terço das empresas pesquisadas, geralmente apresentam uma síntese dos principais indicadores (que, naturalmente, variam muito de caso para caso), enfocando principal-

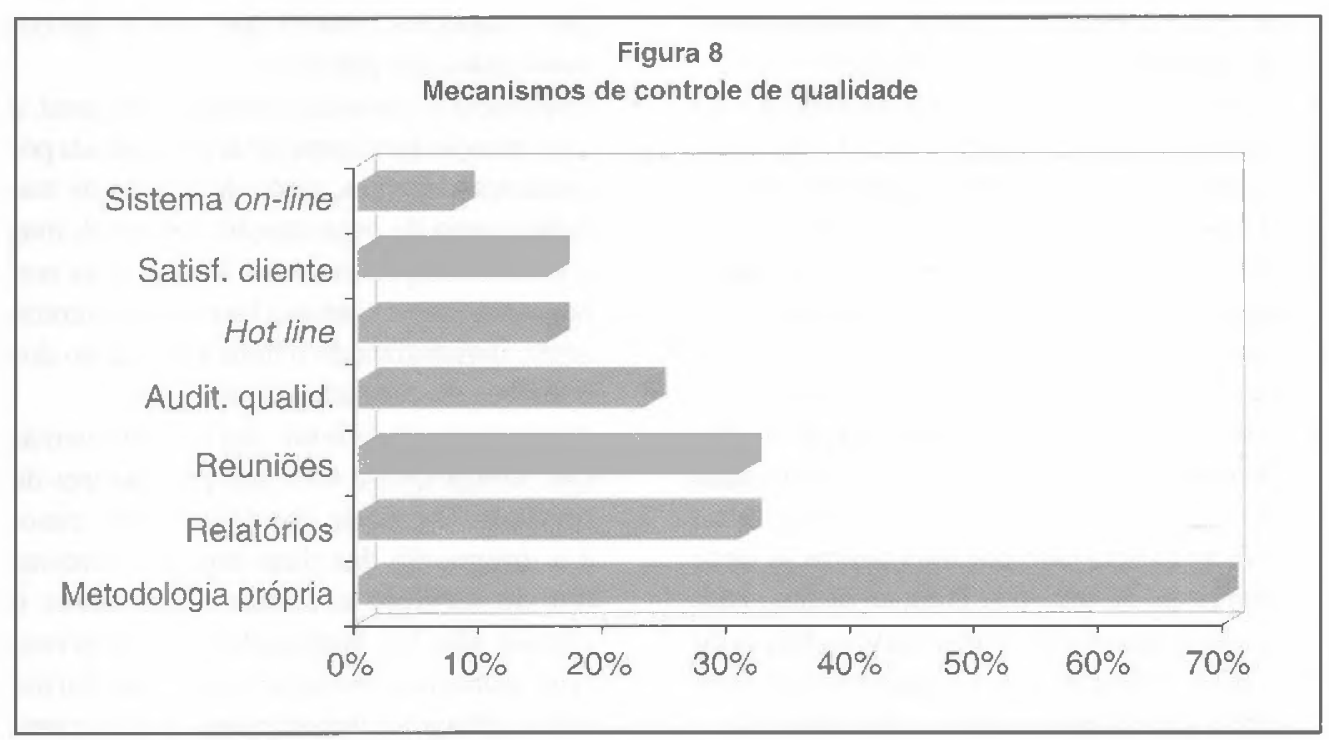

RAE • v. 37 - ก. 4 - Out./Dez. 1997 
mente os resultado no mês e a evolução histórica;

- reuniões sistemáticas são utilizadas por um terço das empresas e visam oferecer ao cliente oportunidade para se manifestar quanto a quaisquer desvios em relação a suas expectativas;

\section{Principais dificuldades enfrentadas}

Quando se concebeu a presente pesquisa, este era o principal tópico que se tinha em mente na qualidade de objeto da investigação. Vale lembrar que o levantamento empírico foi feito através de um roteiro de entrevistas pessoais, com respostas totalmente em aberto. Nessas circunstâncias, sem qualquer indução ou estímulo, ao serem inquiridos sobre os principais problemas enfrentados, os entrevistados citaram os seguintes problemas (ver, também, figura 9):

- resistência do cliente ao processo de terceirização: naturalmente, esperava-se alta incidência de problemas relacionados à resistência interna do cliente: isto é reconhecido pelas próprias empresas que

- auditoria de qualidade, adotada por um quarto das empresas pesquisadas, compreende um levantamento sistemático, independente, que compara os resultados obtidos com os esperados;

- hot line (canal telefônico aberto especialmente para o cliente), amplamente difundido no exterior, tem uma presença tímida no contexto brasileiro: é utilizado por apenas um sexto das empresas da amostra. Em geral, a existência de hot line representa, para o cliente, um importante suporte, principalmente do ponto de vista psicológico;

- avaliação sistemática da satisfação do usuário, feita geralmente através de questionários, é um recurso igualmente utilizado por apenas um sexto das empresas. $\mathrm{O}$ pressuposto dessa abordagem é que, independentemente dos demais indicadores, a satisfação do cliente é o melhor indicativo da qualidade dos serviços prestados;

- sistema on-line para monitorização do desempenho (tempo de resposta, velocidade de transmissão, transações efetuadas etc.) é recurso utilizado por uma dentre as treze empresas da amostra. Trata-se de um sistema permanentemente disponível, através do qual o cliente pode, a qualquer momento, obter informações sobre o desempenho. terceirizam. ${ }^{17}$ Porém, a ocorrência chega a surpreendentes $77 \%$. Na opinião das empresas entrevistadas, a resistência não vem somente do pessoal técnico, mas também dos próprios usuários, que sentem que talvez perderão seu poder no momento em que deixarem de ser "donos" das informações. E a pior resistência é implícita, aquele boicote surdo que geralmente se materializa em informações que não se confirmam ou em "esquecimentos" com relação a aspectos críticos que nunca são comunicados aos parceiros;

- resistência a mudanças internas: em geral, a terceirização precisaria ser acompanhada por mudanças internas, tanto de rotinas de trabalho como de organização funcional, mas o cliente simplesmente se furta a essa responsabilidade e continua fazendo tudo como antes, inviabilizando o bom andamento dos trabalhos do prestador de serviços;

- despreparo do cliente para a terceirização: atinge quase $40 \%$ dos prestadores de serviços. O grande obstáculo, neste caso, é a integração das duas equipes (prestador de serviços e cliente). Por vezes o cliente não foi preparado para conviver com parceiros externos, age de forma indisciplinada e desordenada, não se com- 
promete, não age como co-participante de uma parceria, não atribui claramente as responsabilidades de seu pessoal. Freqüentemente, não tem metodologia de trabalho, não se planeja e desperdiça o tempo do prestador de serviços desmarcando reuniões na última hora ou não cumprindo suas responsabilidades. As vezes a terceirização envolve o uso de tecnologias ou metodologia que o cliente năo domina $e$, mesmo assim, hesita em oferecer treinamento adequado a seu pessoal para viabilizar o trabalho em parceria. Também é comum o cliente insistir em manter sistemas paralelos, o que acaba por desacreditar o serviço prestado pelo parceiro externo. Outro problema usual é o baixo nível de comprometimento da alta direção, que inicia o processo mas depois se omite quando surge a necessidade de decisões sobre questōes críticas ou politicamente delicadas;

- imprecisōes na especificação do serviço a ser executado: levam a produtos que não atendem às necessidades do cliente, causando atrasos e custos excessivos. Tais imprecisões acontecem principalmente por falhas de comunicação (o cliente está tão ha- ainda que ajam com boa vontade, têm dificuldade em materializar e transmitir as informaçōes para o parceiro) e má vontade (reflexo quase que inevitável da resistência interna, pode vir tanto do pessoal de sistemas como dos próprios usuários);

- pressōes políticas do cliente: atingem um terço das empresas e vão desde disputas internas (exemplo: a polêmica entre os que defendem e os que condenam a terceirização) até tentativas de "queimar" executivos usando-se como desculpa a terceirização;

- excesso de expectativas do cliente: atinge um quarto dos prestadores de serviços. $\mathrm{O}$ excesso de expectativas tende a "queimar" o fornecedor de serviços na medida em que, não obstante os esforços deste último, sempre restará a sensação de que não se atingiu aquilo que era esperado. É relativamente comum o cliente aumentar o escopo do projeto e insistir em manter o orçamento e o prazo originais. Esse problema pode assumir uma dimensão tal, que um quarto das empresas da amostra declararam que têm uma área interna especificamente dedicada à administração das expectativas do cliente.

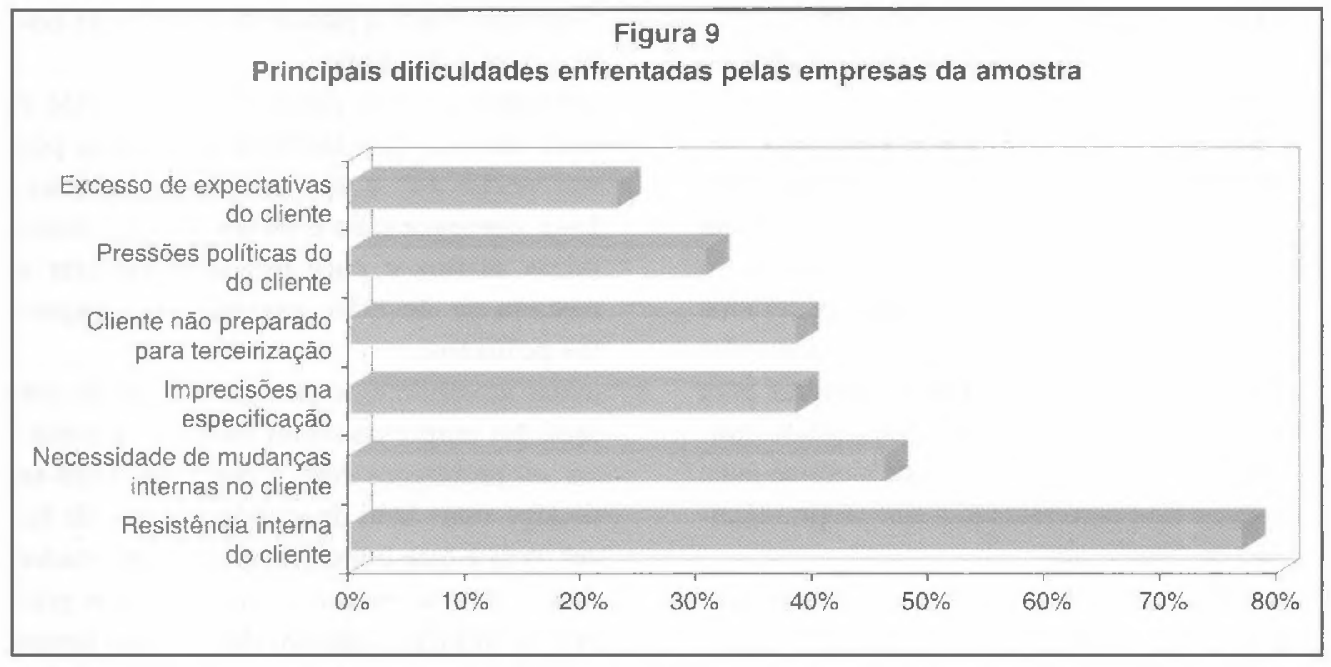

bituado a certos raciocínios que parte do ingênuo pressuposto de que o parceiro externo compreende tudo de imediato, esquecendo-se de que este último não conhece bem o histórico, o contexto e a cultura da empresa), indisponibilidade de dados (grande parte do que existe não está sistematizado, sendo frequientemente baseado nofeeling de algumas poucas pessoas que,

\section{Superação das dificuldades}

Segundo o tópico anterior, quase a totalidade das dificuldades tem sua origem junto ao cliente. Assim, as açōes para superar as dificuldades estão focalizadas no cliente, com medidas preventivas e corretivas em várias frentes simultâneas (figura 10):

- investir no comprometimento do cliente é uma tática citada por $38 \%$ das empresas. 
Isso se faz por vários várias caminhos: no nível operacional, promovem-se desafios profissionais e projetos em parceria, que fazem com que o pessoal do cliente sintase co-responsável pelo trabalho; já com o pessoal da alta administração, a abordagem é no sentido de mostrar-lhes o que está em jogo para que haja senso de responsabilidade quanto às decisões a tomar;

- a transparência no relacionamento é buscada por um terço das empresas, que declaram evitar, a qualquer custo, ocultar problemas. A transparência é vista por essas empresas como um ingrediente fundamental para a consolidação da confiança no longo prazo. Mesmo correndo riscos, preferem que o cliente esteja ciente de todos os problemas enfrentados no transcorrer do trabalho. Tal postura considera que, frequientemente, $o$ cliente pode contribuir ativamente para a superação dos obstáculos se tiver uma visão clara sobre o que está acontecendo;

- mostrar para o cliente os benefícios obtidos é uma abordagem adotada por um quarto das empresas e visa melhorar a motivação, refletindo em maior comprometimento. Por mais que isso possa soar como uma jogada de marketing, é importante fazer com que o cliente tenha uma percepção dos benefícios já alcançados, pois sua tendência natural é concentrar-se nos problemas. Mostrar para o cliente o que vem sendo conseguido contribui, inclusive, para que este sinta-se mais confortável com relação à sua própria decisão de terceirizar;

- o relacionamento social entre a equipe própria e o pessoal do cliente é estimulado por um sexto das empresas. Com esta finalidade, promovem-se eventos como atividades esportivas, jantares de confraternização e outros, visando uma maior aproximação entre os dois lados envolvidos. Note-se que esta ação concentra-se mais no nível operacional;

- a identificação e conquista de aliados é a preocupação de um sexto das empresas, que buscam identificar, no cliente, quem poderia ser um elemento de ligação mais dispos- to a colaborar e quebrar barreiras internas. Trata-se de um investimento de retorno garantido;

a gerência de contas, utilizada por um sexto das empresas, consiste em ter alguém em contato permanente com o nível gerencial do cliente, buscando o compromisso da alta direção;
- o estímulo à qualificação do cliente também foi citado por um sexto das empresas, visto que grande parte da insatisfação prende-se ao fato de que o usuário não conhece bem aquilo que lhe está sendo oferecido. Nesses casos, à medida que aprende a tirar melhor proveito dos recursos disponíveis, o usuário tende a passar da posição de crítico para a de aliado;

- entender o ciclo decisório do cliente é uma medida que também foi citada por um sexto das empresas entrevistadas. Essa compreensão é buscada para minimizar atritos e para procurar agilizar a tomada de decisão, evitando-se desgastes políticos;

- evitar envolvimento político foi citado por uma das empresas como forma de minimizar os problemas com o parceiro. Trata-se de algo mais fácil de se falar do que de fazer, pois é quase inevitável que o prestador de serviços acabe por se aliar a alguns grupos de influência dentro da empresa tomadora de serviços, até porque sua sobrevivência em longo prazo pode depender disto.

\section{Fatores críticos de sucesso}

Pediu-se a cada entrevistado que citasse, em ordem decrescente de importância, pelo menos três dos fatores críticos de sucesso em seu negócio, podendo mencionar tantos quantos desejasse. Como não havia resposta induzida, o resultado foi pulverizado e disperso. 


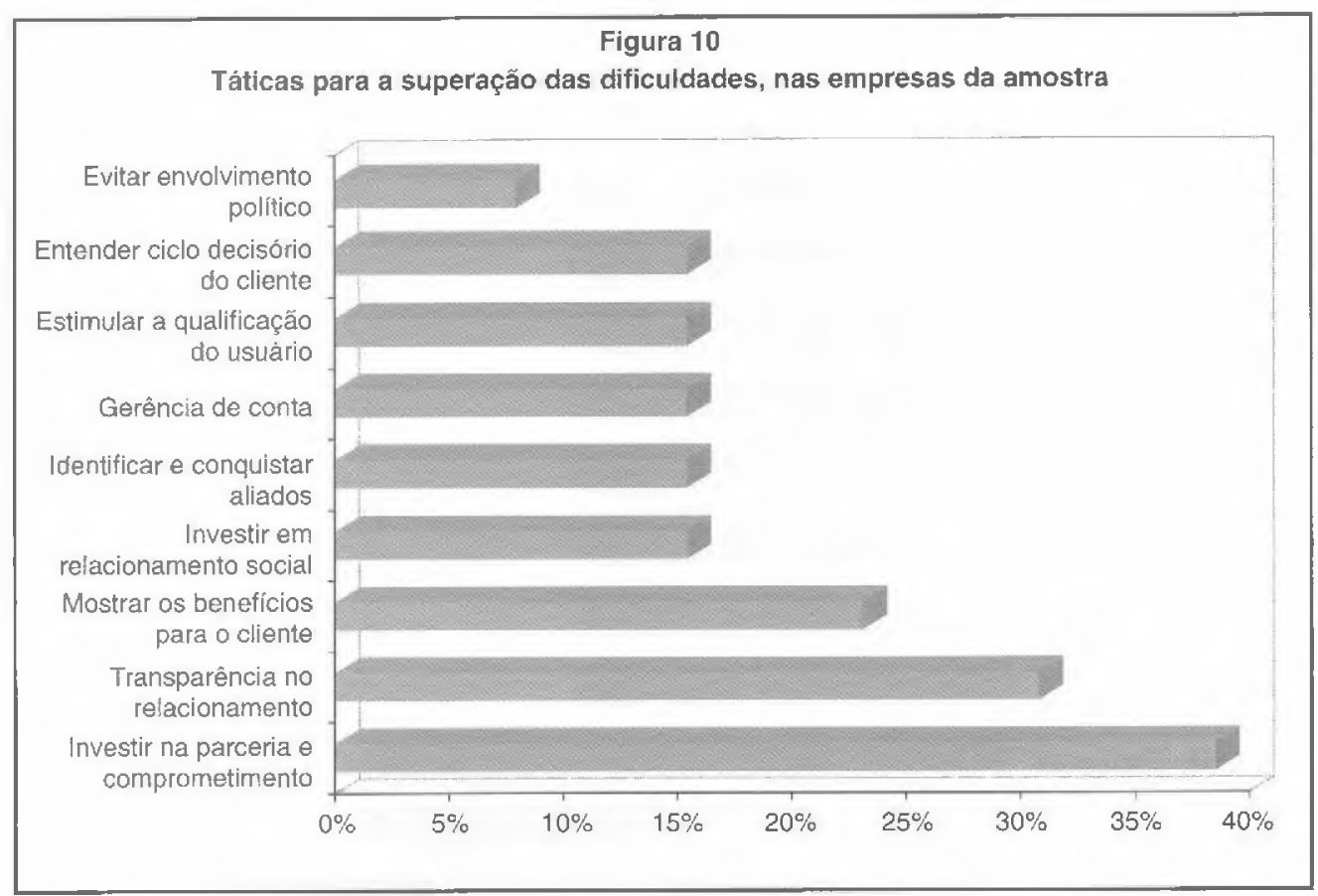

Na percepção dos entrevistados, os dois fatores mais importantes, citados por um terço das empresas, são a qualidade do serviço e a customização (capacidade de oferecer uma solução ajustada às particularidades do cliente dentro de um orçamento razoável).

Num segundo patamar, foram citados por um quarto das empresas a capacitação técnica da equipe e o acompanhamento para melhorar as condições da implementação.

Finalmente, houve outros oito fatores citados por um sexto das empresas: a abrangência dos serviços (oferecer ao cliente uma solução completa); a atualização tecnológica; a flexibilidade da equipe (conhecimentos amplos e diversificados); a experiência internacional (que permite transferir experiência de outros projetos, de forma que o cliente nunca fique sem solução); infra-estrutura e instalaçōes físicas adequadas; o uso de metodologias que assegurem a consecução dos projetos; o bom relacionamento com o cliente (busca da maior cordialidade possível); e sucessos anteriores (que "fazem o nome" da empresa).

Houve ainda oito fatores com menção única: capacidade de inovação (transformar a tecnologia em oportunidades para o cliente); capacidade de investimento (para acompanhar a crescente complexidade tecnológica); foco em nicho de mercado (especializar no atendimento a um tipo específico de cliente); independência tecnológica (não se vin* cular a fornecedores ou plataformas tecnológicas específicas); marketing agressivo (maciça presença na mídia especializada); estabilidade do pessoal próprio (contratado com registro em carteira, tem maior motivação); parcerias com outras empresas (para oferecer ao cliente um pacote completo de soluções com o que de melhor existe no mercado); e, finalmente, rede de telecomunicações de grande abrangência, já em operação e disponível aos clientes.

\section{Impacto de novas tecnologias}

Foi perguntado às empresas como elas viam os impactos das novas tecnologias em seus negócios. O que surpreende é a forma significativamente homogênea como o problema é percebido. Embora com palavras diferentes, todas as empresas declararam uma dualidade:

- ameaça: por um lado, a tecnologia representa uma ameaça permanente de se perder o compasso com a concorrência. Há uma percepção de que o produto disponível é "perecível" e o barateamento da tecnologia é visto como a derrubada da antiga barreira existente para os novos ingressantes, aumentando ainda mais a concorrência no setor. Há inúmeras vertentes e nem todas vingam, de forma que é preciso avaliar constantemente quais as frentes com maiores chances de sucesso. Por vezes as mudanças tecnológicas têm levado as empresas a rever suas estruturas, cri- 


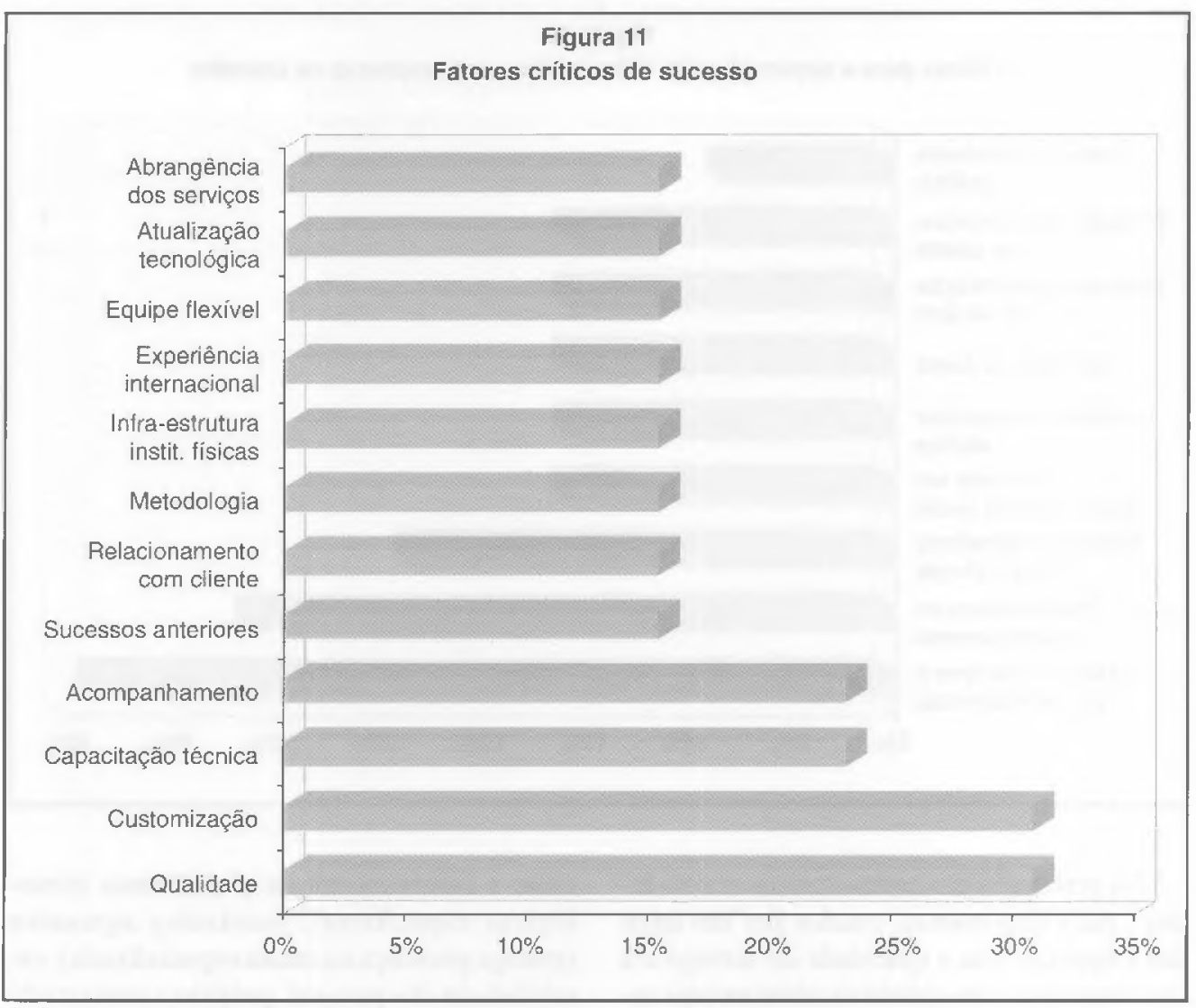

ando novas áreas funcionais para tratar de problemas específicos;

- oportunidades: por outro lado, a evolução da tecnologia tem trazido, a cada dia, novas oportunidades de negócio. Como o ritmo é frenético e a amplitude de soluções é enorme, fica difícil, para o cliente, acompanhar tudo. Desta forma, o prestador de serviços acaba sendo uma solução cada vez mais utilizada.

\section{Planos para o futuro: nichos de atuação}

Foi perguntado o que as empresas pretendiam quanto a seu foco de atuação, ou seja, manter, ampliar ou concentrar. A figura 12 revela a tendência de se ampliar o leque:

\section{Planos para o futuro: focalização de produtos e serviços}

Quanto aos planos relativos a concentração dos produtos e serviços, dois terços pretendem seguir com a situação atual e os restantes pretendem aumentar a focalização, conforme figura 13 .

\section{Planos para o futuro: base de clientes}

A figura 14 ilustra a preocupação em am-

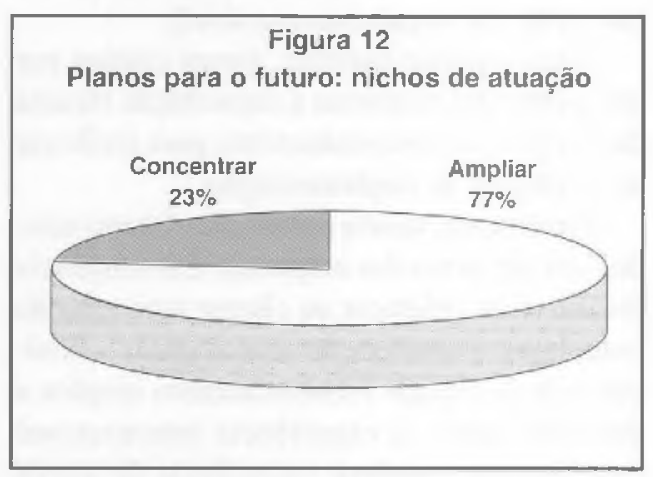

Figura 13

Planos para o futuro: focalização de produtos e serviços

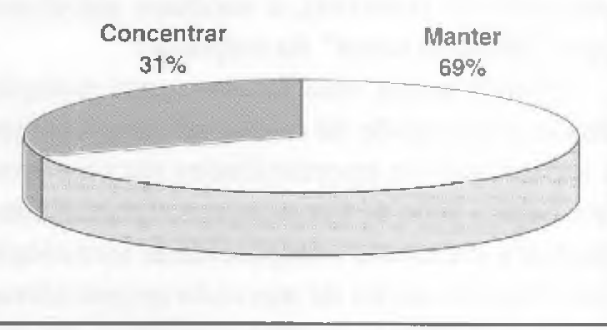


pliar a base de clientes, reduzindo assim o risco de dependência em relação a clientes isolados.

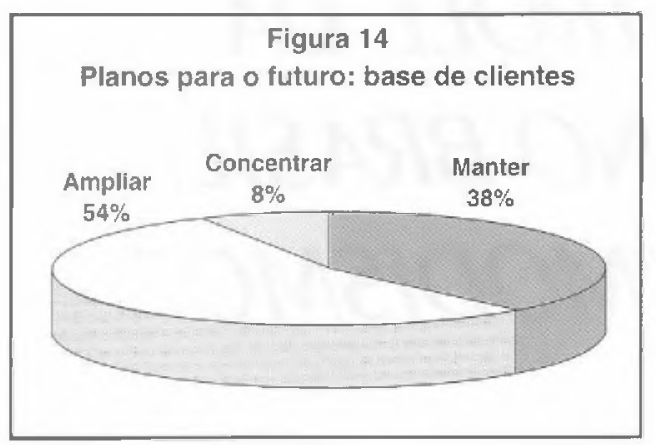

\section{Planos para o futuro: tecnologia}

Quanto aos planos para o futuro, foi grande a dispersão. Um terço das empresas quer apenas acompanhar tendências em geral, sem ênfase em nenhum ponto específico; outras enfatizam as arquiteturas abertas e a maior independência possível em termos de plataformas de hardware e de software; outras querem passar a utilizar GUI (Graphical User Interface), cientes da crescente demanda por interfaces gráficas; e uma das empresas pretende montar um show-room para mostrar, para os clientes em potencial, quais as tecnologias disponíveis. confirmando na prática a tendência percebida intuitivamente. Essa intensificação das parcerias ocorre porque, cada vez mais, o prestador de serviços oferece ao cliente uma solução completa e integrada, encarregando-se de buscar no mercado tudo o que for necessário. Com a crescente complexidade e dispersão tecnológica, é cada vez mais difícil um único fornecedor dominá-las todas. Quanto ao cliente, não precisa preocupar-se com nada, visto que contrata um único parceiro e este se encarrega do processo de integração como um todo. Pode-se dizer que esta tendência configura um novo patamar de maturidade do mercado de serviços em informática.

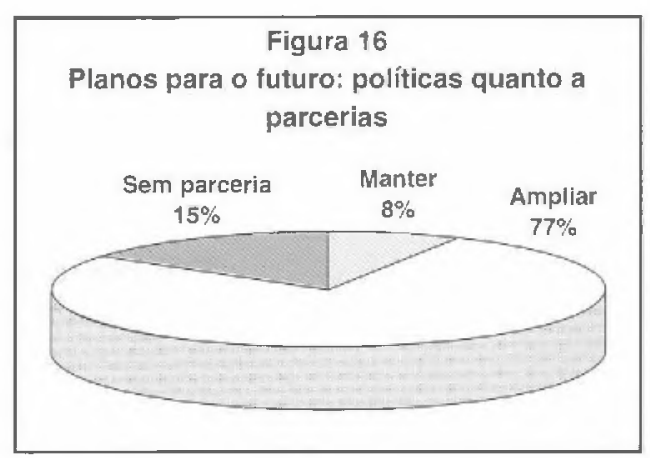

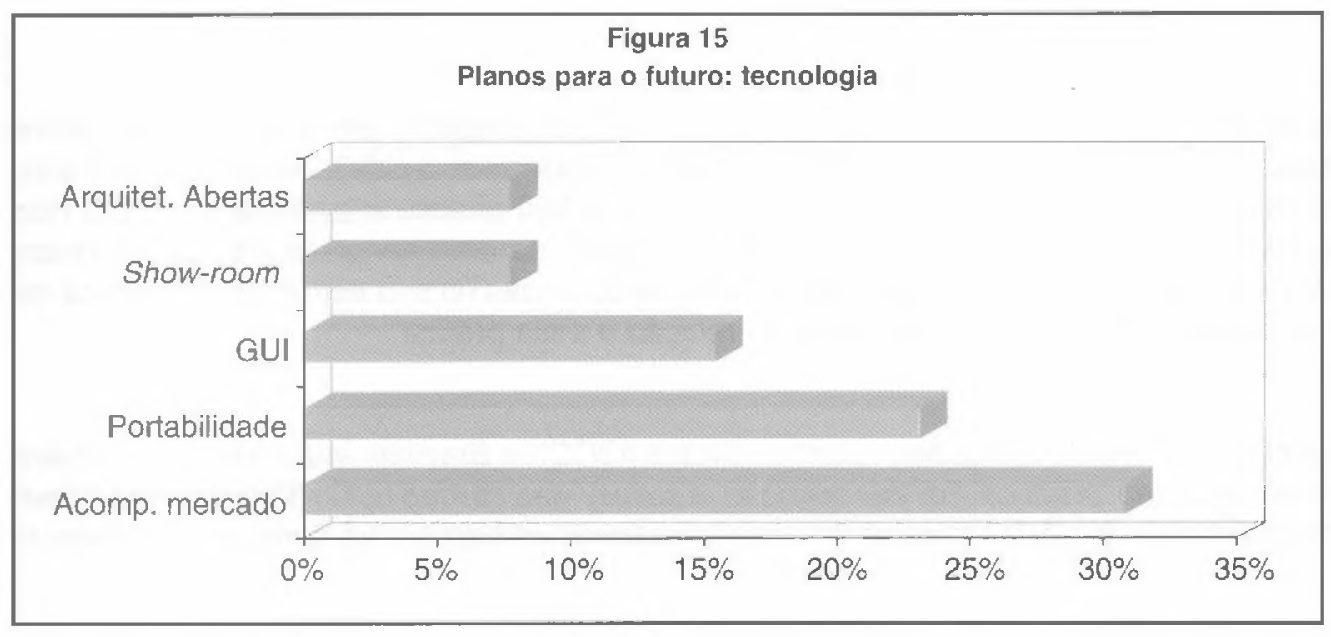

\section{Planos para o futuro: políticas quanto a parcerias}

Ao se iniciar está pesquisa, acreditava-se que esse mercado tende à busca de parcerias e alianças entre empresas que até há pouco se viam como concorrentes. Por isto, foi colocada uma pergunta explícita sobre a questão das parcerias com outras empresas. Três quartos dos prestadores de serviços ampliarão as relações de parcerias com outras empresas,

\section{COMENTÁRIOS FINAIS}

Como conclusão, deve-se ressaltar que, apesar dos problemas relacionados neste e em outros trabalhos, a perspectiva é de crescente amadurecimento na relação entre cliente e prestador de serviços de informática. Ambos os lados estão aprendendo já há algum tempo e tudo indica que evoluem em direção a um relacionamento de parceria mais estável. 